\title{
Agribusiness, Agrienergy and Leadership: The Coaching as a Tool to Guide Talents
}

\author{
Nilo Sylvio Costa Serpa ${ }^{1}$, Bruna Brasil Sá ${ }^{2}$, \\ Ivanir Costa ${ }^{3}$, and Oduvaldo Vendrametto ${ }^{1}$ \\ 1 UNIP - Graduate Program in Production Engineering, Brazil \\ 2 FAJESU - Undergraduate Program in Business Administration, Brazil \\ 3 UNINOVE - Graduate Program in Production Engineering, Brazil \\ niloserpa@gmail.com, brunabrasil21@hotmail.com, \\ icosta11@live.com, oduvaldov@uol.com.br \\ http://www.unip.br
}

\begin{abstract}
This article aims to propose an application of coaching in agrienergy sector. Given the visible growth in demand for renewable energy sources, and the related need to training professionals to deal with the challenges of this branch of agribusiness, the study shows how the coach, the person who pursues coaching, can act to aid those individuals that have potential to exercise leadership in management of agrienergy. The subject is presented and discussed facing the current state of Brazilian agribusiness and treated primarily from an ethical standpoint concerning environmental sustainability.
\end{abstract}

Keywords: growth, leadership, energy, renewable sources, coaching.

\section{Introduction}

During the last 10-15 years, the paradigm shift from a simple technical professional or specialist to an interdisciplinary manager, who makes decisions based on diverse knowledge, has led to an intense search for leaders who can drive projects with quality and effectiveness towards the corporate goals. In this sense, it is growing the demand for tools that may assist the search and preparation of leaders with the speed required by modern world. Coaching is presented as an objective option for this task.

The XXI century is being the scenario of profound changes in professional and interpersonal relationships, mainly because of the social effects of globalization, frantic advances in technology, increasing acquisition of knowledge and change of business paradigm from products to services. These changes will continuously affect the modes to using skills and individual talents. The intitutional patrimony in human assets (special abilities, skills, sense of responsibility, etc.) is passing to the status of the main competitive advantage of a corporation. Business world is now widely changeable and uncertain, more than ever demanding resilient leaderships with high degree of adaptability.

Looking through the prism of energy potential and continental geophysical characteristics as a tropical country by excellence, Brazil offers unbeatable conditions to occupy a prominent place in agribusiness. Compared to the rest of the

B. Grabot et al. (Eds.): APMS 2014, Part II, IFIP AICT 439, pp. 38 452014.

(C) IFIP International Federation for Information Processing 2014 
world, it presents a wide availability of fertile lands which allows the cultivation of various species. It also has considerable technological legacy in biofuels, a fact that puts Brazilian nation in unique position in global economy.

Given the above comments, present study was produced to render the conviction that business coaching will be soon an indispensable tool for agile processes of discovery and preparation of leaders for great magnitude sustainable projects, as well as for organization of modern human resources management. Being agribusiness one of the most promising, profitable and important sources of means for human survival against the inexorable fact of the extinction of fossil energy resources, it is essential that efforts are taken to prioritize the retention of the best teams in the field of agrienergy. Specific goals of this study are 1)the stimulation of interdisciplinary debates (pedagogical, sociological and educational) among professionals and scholars interested in this subject, 2)- the prelusive search of elements that enable a renewal of the dynamics of labor relations in agribusiness faced to the advent of agrienergy as an alternative for human survival, 3)- the delimitation of a green governance structure whose leaders have not only aware of their roles, but sureness about their career choices. Such goals will certainly be guided by ideas brought by coaching.

\section{Theoretical Frame}

\subsection{Breaking Some Myths}

It is a very common mistake to consider "non-scientific" a work implemented on a completely new and unexplored area. If this view were taken seriously, it would be impossible to advance knowledge precisely because the latter is accelerated by reflections and conjectures based on more or less general observations on certain trends. It seems that people have forgotten that there is no understanding of what is observed without theory. The collapse of culture from the second half of the twentieth century began precisely with the post-modern delusions with no solid conceptual basis. If we had to wait long years to say something based only on data collected we would be sterile of ideas and ability to drive and create our own destinies.

Liking it or not, it is also obligation of science to open conceptual and theoretical windows so that we can get as fast as possible to the state-of-art where it will be possible to confront, refute and refine our initial models. The lack of foresight and pioneering spirit has led to a poorly creative decade, despite all the technology currently available. Today, novelties are results of collages from existing technologies more than genuinely innovative contributions. Indeed, there are very few papers in all fields of knowledge that are now considered indisputable contributions. Several papers have been published based on insufficient data only to give a more realistic aspect to the matter when it would be more productive and consistent to recognize the lack of sufficient data, working on a theoretical level, organizing conceptual models capable of being thoroughly tested over the years. Barring initiatives of this kind is not loss for the authors, but for an entire youth community waiting for new stimuli of research and creation. 
This article is only intended to open rational windows, not to exhaust a topic that is just beginning to awaken interest in corporate environments. Coaching is still a young discipline, opened to many suggestions and investigations. The best results reported in the literature are still partial and inconclusive. International experts acknowledge that many coaching skills programs are introduced and fail [15. Nevertheless, at the same time they recognize that after several years of trial and error, the application of neuroscience in coaching seems to shed new light on human/business behavior [15]. It will take a long time to earn enough data about coaching's real efficiency in corporate environments. So far, studies have been conducted mainly at the theoretical level with the help of contributions from some fields as pedagogy, psychology and management, and, from now on, neuroscience. Accordingly, papers as the present work should be encouraged to encourage new research teams.

\subsection{The Origins of Coaching and Its State in Brazil}

As pointed out by Corrêa and Slaughter in a study conducted by the Institute Humanitatis, coaching is a technique that introduces a continuous process of high-level relationships in order to assist the identification of skills and leadership potential [3]. Through meetings, the customers choose the focus of conversation while the coach (professional who performs tasks of coaching) will contribute from listening with questions and suggestions.

Also in accordance with the above study, coaching has origins in tennis and golf. In these sports it was clearly the essence of coaching: releasing the potential of an individual to maximize their performance, helping him to learn about himself and by personal effort, rather than teaching. The English word "coach", most likely from Hungarian "Kocsi", means carriage, vehicle widely used in the eighteenth century. Thus, it is believed to have been used metaphorically to describe the tutor of the eighteenth century, which led the education of children by the various fields of knowledge, just as the carriages carrying the families in the fields of England.

The use expanded until today and it has been established the following words: Coaching - is the process; Coach (coaches in plural) - is the professional qualified to perform the process; Coachee (or client) - is the person who receives coaching. There is, however, as in every area in its infancies, the risk of misinformation and unauthorized appropriation of the title of coach by people without the knowledge and training appropriate to the exercise of coaching in its fullest and utmost responsibility. Asked about the relevance of the topic in Brazil, Andrea Lages, Master Trainer in Coaching, comments that in Brazil coaching gained much strength in recent years and continues to grow. She points that the problem we face is with regard to people who are trying to take advantage of the situation and adopt the title of coach with complete informality, often without knowing what it really means. On the other hand, she says, this reflects the popularity of the profession in the country [11.

From here, we take important lesson for those interested in the career: always seek an institution duly licensed to perform research and provide training in 
coaching; it is a matter of professional life of people with direct impact on their personal lives, their affections and desires.

\subsection{The Coaching and Its Contribution to the Formation of Ethical and Competent Leadership}

The literature on coaching is gradually growing. Authors such as Batt [2], Downey [4, Ely et al. [5], Karawejczyk and Cardoso [8], John and West-Leuer [10], Motter Junior [12] and Whitmore [17, show what can be expected from the action of the coach. There is a consensus among these authors that the coaching is based on several areas of knowledge to build your method; they include psychology, education, pedagogy, business management and even aspects related to spirituality and religion, according to the precepts of Motter Junior 12. Recently, as already noted, new contributions coming from neuroscience have expanded the scientific perspectives of the application of couching [15].

The coaching is focused on leaders, either individuals or team leaders, giving emphasis on action oriented by the more evident skills of the coachee, that is, the human-target of professional coaching. It is not, therefore, therapy, since is distinct the way to provide services, neither mentoring which requires a mentor positioned between the guide that gives support and the driver that dictates rules and paths. The coach is neither one thing nor the other, just a "poker", an instigator whose intervention generates free response of the person in their professional context. In practice, it is true, the intervention of the coach combines elements from other disciplines, but it is his ethical responsibility to bring their actions within the limits of its authority which makes productive such intervention since it does not conflict with the personal characteristics of the coachee.

There are different ways for corporations avail themselves by coaching. Such evaluation needs not necessarily be related to training programs; it can exist as something autonomous. However, Motter Junior points out a fundamental aspect to be considered in the coaching, saying that each coachee is different and the choice of the coach and the methodological approach (non-standard) will be decisive [12. The latter should be creative, with lots of interactions and self-reflections throughout the process. Reflective practice is proposed to promote learning and change from the action, an awareness process that involves persistent observation and dialogue [12].

In fact, creativity is essential for the activity of the coach, and this is so much clearer the more one gives account of human diversity. In the perspective of Chiavenato, the real difficulty in recruiting and retaining a good work force is not a matter of financial capital, which was once considered essential for business success [9]. This applies to projects of any magnitude. Keeping professionals is not just a question of salary, but a question of motivation and functional suitability to ensure operational sustainability under ever-increasing pressure for results. Agribusiness, and more precisely, the area of agrienergy, is characterized today as one of the spheres of human action under greater pressure for quick results in face of the global expectations about alternative sustainable energy solutions. 


\section{The Importance of Agrienergy}

The authors call "agrienergy" any energy obtained from agricultural sources, and, accordingly this view, the word is a synonym for bioenergy. The term was chosen to maintain a ready lexical and also visceral relationship with "agribusiness", now understood as the set of various business segments, from the production of inputs (seeds, fertilizers, machinery, etc.) until the arrival of final outputs (cheese, crackers, pasta, etc.) to the consumer [16].

Although the word "energy" is freely used in different contexts, the concept of energy is, physically speaking, one of the darkest in science. For practical purposes of common human actions is sufficient to understand that it is a magnitude which turns continuously into work performed by human individuals, machines or animals. This energy is obtained from matter, which is, after all, one of the forms that energy takes. Among the materials more easily convertible by machinary into energy capable of doing work, there are fossil fuels, for example, petroleum and coal, and non-fossil fuels such as vegetable oils and ethanol derived from sugarcane and beet. Beside these, there are indirect sources of the so-called renewable energies, such as hydro, solar, wind and geothermal. The name agrienergy refers to that derived from agricultural matter, that is, organic products such as soya, sugarcane and others.

Energy is absolutely essential to developing the world, as well as steel production. The dynamics of population growth and labor require continuous power to the realization of human activities on the planet. The global reality shows steady growth of energy consumption; so, efforts are needed to increase worldwide production, encouraging the diversification of the energy matrix. In parallel, we need to reduce the impacts on the environment, hence the special attention to more sustainable processes of production. Here is where the promotion of agrienergy becomes imperative. According SEBRAE, in electronic publication on bioenergy, the increase in energy demand will be more significant in countries considered in consolidation of development (China, India, Brazil and Russia), notably in transport, in residential and industrial areas. There is also the need to provide supplies of electricity and coking from modern sources for 2.5 billion people in countries in the early stages of development [14.

Brazil is one of the great suppliers of agricultural products to the world, exporting to many countries. Mainly in terms of domestic consumption, the agrienergy sector is one of the most promising in agribusiness. In 2009, it was estimated that the global demand for biofuel, at that time $3 \%$, would rise to $12 \%$ to $15 \%$ in the ensuing 15 years [14. To get an idea, it is expected that 8 million hectares of land occupied at 2009 by the culture of sugarcane in Brazil shall reach 14 million at 2019 [14. It is not difficult to imagine human demands, logistics and technology required to support such growth. Given this inescapable reality, it becomes cogent to preparing quality human resources in proportion to the dimensions of the challenge. Among the tools that support the task of structuring competent professionals we have the modern executive coaching. 


\section{Successful Experiences with Coaching}

The activity of coaching is still shy. According Karawejczyk and Cardoso, worldwide, there are 16,000 persons empowered in this career, and of those, less than two thousands in Brazil [8]. The growth of Brazilian Society of Coaching is 80$90 \%$ per year, according to president Villela da Matta, who also forecasts an expansion of 30,000 registered members by 2020. Looking at human needs for achievement and accomplishments, surveys show that at least 30,000 individuals have passed through the coaching process in Brazil. The president of the International Coach Federation - Brazil, José Augusto Figueiredo, reports that there are 150 registered Brazilian members in that institution [11].

Therefore, empirical studies on the application of coaching are still scarce. We are at the beginning of a new era, with a wide open field for research and new proposals. It is the role of academies welcoming and motivate their students to the innovative work at the moment in which Brazil can take the forefront in the field, having as main target the formation of competent leaders in agribusiness. From the few available data on the experiences of coaching, the authors count up those divulged by the ABC (Brazilian abbreviation for Brazilian Academy of Coaching). According to a survey organized by this institution, one study commissioned by a Fortune 500 company (annual list compiled and published by Fortune magazine that ranks the top 500 U.S. companies) about its own coaching program showed a return on investment of $529 \%$ discounted the significant and valuable intangible benefits. Another study, now produced by executives from Fortune 1000, showed that companies which received coaching had an average return of 5.7 times the amount spent on coaching. Yet another study, this time conducted in 2004 on executive coaching at Booz Allen Hamilton, a company of business consulting, showed a return of U.S. $\$ 7.90$ for every dollar spent on the program [1. One example of success in Brazil has been the Program for Managerial Development of Itaipu Company, which intensified the application of the methodology of coaching in strategic areas and other investments in training [7].

\section{A Proposal for Coaching in Agribusiness: Agrienergy in Evidence}

Contemporary society has the duty to reduce gas emissions from fossil fuels if it wants to perpetuate on the face of the earth. On the other hand, the depletion of fossil fuels leads inevitably to the search of renewable energy sources. The transition from fossil fuels by the named Green Revolution sets new conceptual paradigms of behavior. The existing and future projects will necessarily be reconstructed according to an ethic of sustainability linked to the idea of generalized wellfare in the world. Given various initiatives, both from governments and society which have been stimulating the production and use of biofuels, how should be the coach's participation in professional organization for the Green Revolution? 
According to a recent survey of the Energy Research Company of the Ministry of Mines and Energy [6], renewable sources contribute $87.2 \%$ to the country's energy matrix in the following manner: $81.2 \%$ water, gas $5.8 \%, 5.6 \%$ sugarcane biomass, oil $3.1 \%$, nuclear $2.6 \%$, coal $1.3 \%$ and $0.4 \%$ wind, which demonstrates the potential worldwide use of these sources in face of the increasing demand for energy. It is in this context that the use of sugarcane as an energy source sounds to be the best of the best, since the country has vast arable lands and appropriate environmental conditions to the crop. Nevertheless, although the prospects for continued performance of agrienergy continue promising, there are structural problems that can wither this success. The environmental issue, mainly because of deforestation that has been observed in areas of soybean expansion, creates a serious sustainability problem that the country must face, otherwise while "solving" a problem on one hand (the stubbornness to find that producing commodities we are in the way of the progress) we are creating another for future generations, more dangerous than the problem "solved". Here, the main function of coaching is to motivate leaders in the ethical sense of a parsimonious planning that exceeds the mere question of immediate financial account, looking at the total range of human needs in the short, medium and long term.

That is not all. In 2009 it was aproved the Federal Law 12.187 establishing the National Policy on Climate Change in Brazil with the objective to voluntarily reduce emissions in a rate projected until 2020 between $36.1 \%$ and $38.9 \%$. This reduction will occur primarily by reducing deforestation in the Amazonia and Cerrado, adoption of good agricultural practices, renewable energy, biofuels and energy efficiency. Leaders need to understand that willful attitudes are actually coming from the extreme sense of responsibility and obligation to society and to future generations. One of the goals of coaching is to aid leaders to render this aspect a key factor for decision-making. With the establishment of an early coaching program for leaderships in managing agrienergy, adopted and widely disseminated by academies and governmental areas, we can start a solid, innovative and reputable project of bioenergy in Brazil, probably coming to be in near future a worldwide reference on sustainability.

With the formation of ethical managers it will be delivered in good hands the responsibility of strategic plannings for sustainable expansion of agrienergy, taking into account issues of paramount importance as the ecological impact of crops for large production of ethanol and biodiesel, the ethics of producing species that serve as well to feed the starving populations as to supply energy, the standards for responsible exploitation of the soil with mandatory quotas of replacement and, finally, honesty in choosing the best energy source for every situation well analyzed.

\section{Conclusion}

This work dealt with the application of coaching in agribusiness, specifically in the area of agrienergy. It discussed the contribution of coaching to the preparation of leaderships for the management of agrienergy. It showed the importance 
of creating new leaders strongly linked to the ethical principles of sustainability with regard to the exploitation of biomass as a renewable energy source. Although this is a research on a discipline considered new in the market, the work met favorable impressions on the coaching and pointed examples of success in other business areas, showing its potential for improving individual performance, personal satisfaction and indicators of productivity and quality. It is expected that the work shall stimulate greater interest in academic and business circles, motivating further research on the topic. To those people preferring to wait long years for data so that one can validate a pioneering model, this paper makes a prospect of intellectual action against the sedentary mindset that has prevailed in emerging countries.

\section{References}

1. ABC - Academia Brasileira de Coaching: Pesquisas Sobre os Benefícios do Coaching, http://www . abracoaching.com.br

2. Batt, E.: Cognitive Coaching: A Critical Phase in Professional Development to Implement Sheltered Instruction. Teaching and Teacher Education 26, 997-1005 (2010)

3. Corrêa, M., Abate, P.: O Processo de Coaching em uma Abordagem Transpessoal. Instituto Humanitatis, Campinas, Brasil (2007)

4. Downey, M.: Effective Coaching Lessons from the Coach's Coach. Thomson (2003)

5. Ely, K., Boyce, L., Nelson, J., Zaccaro, S., Hernez-Broome, G., Whymand, W.: Evaluating Leadership Coaching: A Review and Integrated Framework. The Leadership Quarterly 21, 585-599 (2010)

6. EPE - Empresa de Pesquisa Energética, http://www .epe.gov.br/Estudos/Paginas/default.aspx?CategoriaID=345

7. Itaipu Binacional: Relatório de Sustentabilidade (2011), http://www.itaipu.gov.br/responsabilidade/relatoriosdesustentabilidade

8. Karawejczyk, T., Cardoso, A.: Atuação Profissional em Coaching e os Desafios Presentes e Futuros nesta Nova Carreira. In: B. Téc. SENAC: a R. Educ. Prof., Rio de Janeiro (2012)

9. Chiavenato, I.: Gestão de Pessoas: E o Novo Papel dos Recursos Humanos nas Organizações. Elsevier, Rio de Janeiro (2004)

10. John, E.-M., West-Leuer, B.: Coaching in Multinational Companies an Interdisciplinary Analysis of a Management Consultant Case Narrative. Procedia - Social and Behavioral Sciences 82, 628-637 (2013)

11. Lages, A.: O Coaching, Algo que Funciona, http://www. vocevencedor.com.br/artigos/ personalidades/o-coaching-algo-que-funciona

12. Motter Junior, M.: A Dimensão do Sucesso em Coaching: Uma Aálise do Contexto Brasileiro. Dissertação de Mestrado. FGV, Rio de Janeiro (2012)

13. Rogers, J.: Coaching Skills: A Handbook. Open University Press, Oxford (2007)

14. SEBRAE: Agroenergia, http://www.sebrae.com.br/setor/agroenergia

15. Sherpa Coaching: The executive coaching survey - evidence and interaction. Sherpa Coaching, Cincinnati (2014)

16. Toledo, M.: Decisões no Agronegócio. In: Costa Neto, P.: Qualidade e Competência nas Decisões. Blücher, S. Paulo (2007)

17. Whitmore, J.: Coaching for performance. Nicholas Brealey, London (2002) 